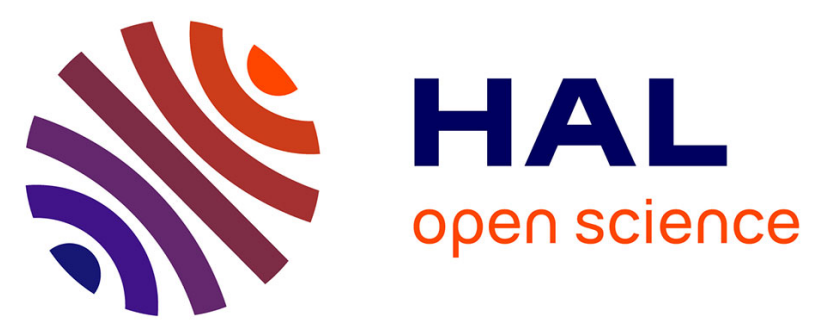

\title{
STUDY OF ELASTIC NON LINEARITY OF SOFT SOLIDS WITH TRANSIENT ELASTOGRAPHY
}

Xavier Jacob, Jean-Luc Gennisson, Stefan Catheline, Mickaël Tanter, Christophe Barrière, Daniel Royer, Mathias Fink

\section{- To cite this version:}

Xavier Jacob, Jean-Luc Gennisson, Stefan Catheline, Mickaël Tanter, Christophe Barrière, et al.. STUDY OF ELASTIC NON LINEARITY OF SOFT SOLIDS WITH TRANSIENT ELASTOGRAPHY. IEEE Symposium on Ultrasonics, 2003, Honolulu, United States. 10.1109/ULTSYM.2003.1293488 . hal-03275036

\section{HAL Id: hal-03275036 \\ https://hal.science/hal-03275036}

Submitted on 30 Jun 2021

HAL is a multi-disciplinary open access archive for the deposit and dissemination of scientific research documents, whether they are published or not. The documents may come from teaching and research institutions in France or abroad, or from public or private research centers.
L'archive ouverte pluridisciplinaire HAL, est destinée au dépôt et à la diffusion de documents scientifiques de niveau recherche, publiés ou non, émanant des établissements d'enseignement et de recherche français ou étrangers, des laboratoires publics ou privés. 


\title{
STUDY OF ELASTIC NON LINEARITY OF SOFT SOLIDS WITH TRANSIENT ELASTOGRAPHY
}

\author{
Xavier Jacob, Jean-Luc Gennisson, Stefan Catheline*, Mickaël Tanter, Christophe Barrière, Daniel Royer \\ and Mathias Fink \\ Laboratoire Ondes et Acoustique, ESPCI, Université Paris VII, \\ U.M.R. C.N.R.S. 7587, 10 rue Vauquelin, 75231 Paris cedex 05, France.
}

Abstract - Transient elastography has shown its efficiency to map the elastic properties of soft tissues. Now like other elastic imaging techniques (sonoelastography or magnetic resonance elastography) transient elastography is faced to the following problem : in order to properly discriminate tumors, additional information such as viscosity, anisotropy or nonlinearity is needed. If nonlinearity has long been studied in metals, crystals or rocks, only a few experimental works are found in the literature concerning soft tissues and none on shear waves. Thanks to the ultrafast scanner that can map the displacement field of shear waves, we present in this paper an overview of three experiments that allow to illustrate and quantify the nonlinear behavior of soft tissue phantoms. In the first one, a static stress is applied on an Agar-gelatin based sample. The change on the shear wave speed characterizes the nonlinear elastic Landau moduli $(A=50 \mathrm{kPa}, B=7 \mathrm{GPa}$, $C=11 \mathrm{GPa}$ ). The surprising difference found between these constants are thought to be closely related to the huge difference between the linear Lamé coefficients $(\lambda>>\mu)$. It is the acoustoelasticity experiment. In the second one, we present an experimental observation of a shock shear wave. The very weak Young's modulus of the tissue phantom allows one to generate plane shear wave with a Mach number as high as unity. In this extreme configuration, the agreement with the numerical simulation of the modified Burgers equation is remarkable. It is the finite-amplitude shear wave experiment. At last, the interaction between two plane transverse waves with frequencies $\omega_{1}$ and $\omega_{2}$ is carefully studied. Harmonics and secondary waves are created during the propagation at the frequencies $\left(3 \omega_{1}, 3 \omega_{2}, \omega_{1}+2 \omega_{2}, \omega_{1}-2 \omega_{2}, \omega_{2}+2 \omega_{1}\right.$, $\left.\omega_{2}-2 \omega_{1}\right)$. It is the nonlinear interaction experiment. The nonlinear coefficients deduced from the two latter experiments are comparable to the order of magnitude of the Landau coefficients found from the first experiment.

\section{INTRODUCTION}

In this paper, we present an experimental study of the nonlinear behavior of an Agar-gelatin based phantom by using an ultrafast ultrasonic scanner. It includes a medical ultrasonic array $(5 \mathrm{MHz})$ with 128 channels [1]. Each channel is connected to a large memory (2 Mbytes), and the echoes are sampled at $50 \mathrm{MHz}$ and digitized with 9 bit resolution. In a typical experiment, 250 echographic images (at a $3000 \mathrm{~Hz}$ frame rate) are recorded in memory.

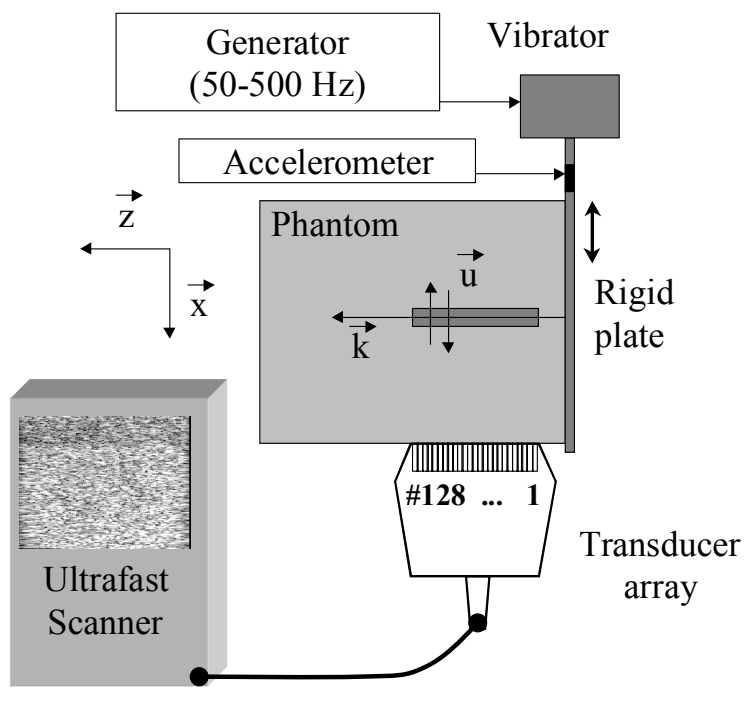

Figure 1: Experimental set-up. Transient elastography technique: a medical transducer array connected to an ultrafast scanner insonifies a tissuemimicking phantom. A $100 \mathrm{~Hz}$ shear wave train is generated by a vibrator from a rigid plate applied on one side of the phantom. Simultaneously, frames (at a $3000 \mathrm{~Hz}$ repetition rate) are stored in memory. With cross correlation algorithms between frames, the transverse displacement field (along the z-axis) of the shear wave is measured along the central axis of the plate (parallel to the $x$-axis).

A displacement movie is obtained using crosscorrelation algorithms between successive speckle images [2]. Thus it allows to detect fast 
tissue motion induced by low frequency shear waves within the medium. The sensitivity of this apparatus allows to detect displacements as small as $1 \mu \mathrm{m}$. The whole technique is known as transient elastography. As shown in figure 1, the low frequency $(100 \mathrm{~Hz})$ shear wave is generated by shaking transversally a rigid aluminum plate $(11 \times 17 \mathrm{~cm})$ applied on one side of the phantom with a vibrator (Brüel\&Kjær, 4809 type). The transverse displacement field of the shear wave is measured in one dimension along the axis of the rigid plate on a distance of $40 \mathrm{~mm}$ which represents a few shear wavelengths. An accelerometer is set on the vibrator to make sure that no harmonic is generated by the source.

\section{ACOUSTOELATICITY EXPERIMENT}

A static uniaxial stress is applied in the $y$ direction. Experimentally, loads are set on a rigid plate placed on the top of the phantom. Then, one can observe changes on the speed measurements of shear waves polarized in the direction parallel ( $y$ direction) or perpendicular ( $x$ direction) to the stress axis, Figure. 2. In order to ensure good contacts in the experiment, a preload is applied on the phantom that explains why the same value of the shear modulus is not recovered at zero stress for both polarizations.

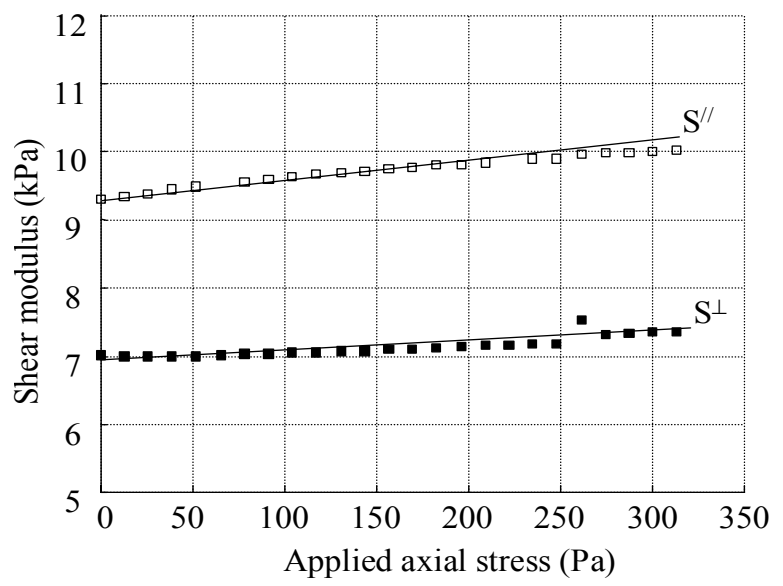

Figure 2 : Experimental shear moduli as function of the uniaxial stress. From the two slopes, the two nonlinear Landau coefficients A and B are computed.

The three plane wave solutions that propagate in a plane perpendicular to the axis of the static uniaxial stress are associated with the three following eigenvalues $[3,4]$ :

$$
\begin{gathered}
\rho_{0} V_{P}^{2}=\lambda+2 \mu-\frac{\sigma}{3 \lambda+2 \mu}\left[-\frac{\lambda}{\mu} A\right. \\
\left.+2 B\left(1-\frac{\lambda}{\mu}\right)+2 C-4 \lambda-\frac{2 \lambda^{2}}{\mu}\right] \\
\rho_{0} V_{S}^{/ / 2}=\mu-\frac{\sigma}{3 \lambda+2 \mu}\left[\frac{A}{2}\left(1+\frac{\lambda}{2 \mu}\right),\right. \\
+B+\lambda+2 \mu] \\
\rho_{0} V_{S}^{\perp 2}=\mu-\frac{\sigma \quad}{3 \lambda+2 \mu}\left[\frac{A}{2}\left(1-\frac{\lambda+\mu}{\mu}\right)\right. \\
+B-2 \lambda]
\end{gathered} .
$$

In equations $(1,2,3), V_{P}$ stands for the speed of the compressional wave, $V_{S}^{\prime \prime}$ for the speed of the shear wave with a polarization parallel to the stress axis, and $V_{S}^{\perp}$ for the speed of the shear wave with a polarization perpendicular to the stress axis. From a quantitative point of view, the shear elasticity is extracted from the first point of the curves (null stress), $\mu=6.35 \mathrm{kPa}$. The perpendicular elastic moduli increase by $4 \%$ and the parallel moduli by $9 \%$ (Figure 2.). From the pair of slopes and using the set of equations $(2,3)$, one can found the following values $-101 \mathrm{kPa}$ and $-14.3 \mathrm{GPa}$ for the Landau coefficients $A, B$ respectively. The huge difference between these third order moduli is striking since in more conventional media such as metal, rocks or crystals they are of the same order. At last, the third order coefficient $C$ is obtained from results found in the literature. Actually, Everbach measured with a thermodynamic method (the pressure is changed while the temperature is kept constant), the nonlinear parameter for longitudinal wave $\beta=3.64$ in an Agar-gelatin phantom [5]. This value of the nonlinear parameter does not change significantly from one sample to another and is in fact close to the parameter found in water, $\beta=3.50$. Since $\beta$ is expressed as function of the Landau coefficients:

$$
\beta=-\frac{3}{2}-\frac{A+3 B+C}{\rho_{0} V_{P}^{2}}=3.64,
$$

and using the experimental value of $A$ and $B$. One finally obtains $C=31 \mathrm{GPa}$ [6]. 
TABLE. 1 Elastic moduli measured in an Agar-gelatin based phantom.

\begin{tabular}{ccccc}
\hline \multicolumn{2}{c}{$\begin{array}{l}\text { Linear second order elastic } \\
\text { moduli (Lamé coefficients) }\end{array}$} & \multicolumn{3}{c}{$\begin{array}{c}\text { Nonlinear third order elastic moduli } \\
\text { (Landau coefficients) }\end{array}$} \\
\hline$\mu(\mathrm{kPa})$ & $\lambda(\mathrm{GPa})$ & $A(\mathrm{kPa})$ & $B(\mathrm{GPa})$ & $C(\mathrm{GPa})$ \\
\hline $6.35 \pm 0.04$ & 2.25 & $-101 \pm 7$ & $-14 \pm 2$ & $31 \pm 3$
\end{tabular}

\section{SHOCK TRANSVERSE WAVE}

In the field of soft solids, such as biological tissues (muscle, fat, breast) or Agargelatin based phantom (a soft tissue model), the very low value of the shear elasticity (typically $2.5 \mathrm{kPa}$ ) allows the propagation of a low frequency transverse wave $(100 \mathrm{~Hz})$ with a very high particle velocity $\left(0.6 \mathrm{~m} . \mathrm{s}^{-1}\right)$ compared to its speed $\left(1.6 \mathrm{~m} \cdot \mathrm{s}^{-1}\right)$. Thus Mach numbers as huge as unity are obtained. Consequently in this peculiar configuration, third order nonlinear effects become very high and clearly modify the transverse wave shape. The temporal shape of the particle velocity at $15 \mathrm{~mm}$ away from the source is not a saw-tooth shape as for the longitudinal waves. From a theoretical point of view, this result is well explained considering the local speed (5).

$$
c=c_{o}\left(1+c_{o} \alpha v^{2}\right) \text {. }
$$

Each point of the wave profile travels with its own constant speed, which depends on the value of the square of the particle velocity $v^{2}$. As a result and contrary to longitudinal wave, the high amplitude parts of the wave travel faster whatever the sign of the particle velocity: the slope steepens simultaneously on the positive and the negative half period (Figure 3(a).). This can be interpreted as a consequence of the symmetric behavior of the displacements field as regard to the propagation direction. As predicted by theory, for such plane waves one can observe only odd harmonics at $100 \mathrm{~Hz}, 300 \mathrm{~Hz}$ and 500 $\mathrm{Hz}$ (Figure 3(b).). As a comparison, the spectrum of the accelerometer set on the vibrator (the shear wave source) only contains the fundamental harmonic at $100 \mathrm{~Hz}$.

The study of the amplitude of each harmonics as function of depth allows to characterize the shock distance. As predicted by the theory, the shock distance increase as the emitted amplitude of the source decrease. This experimental results are confirmed by a finite difference simulation based on McDonald and
Ambrosiano algorithm to compute the modified Burgers equation including viscosity $[7,8]$.

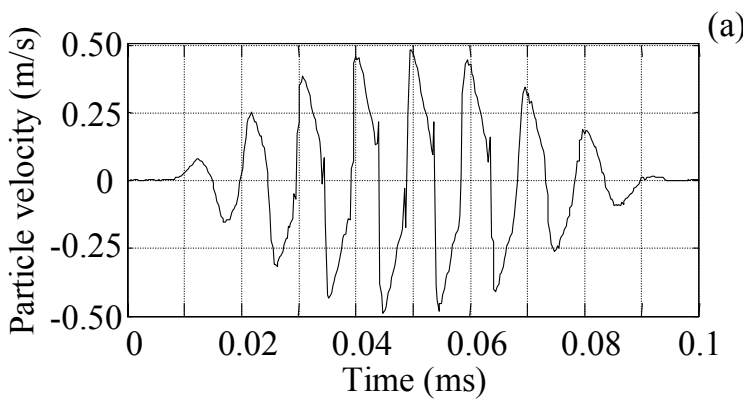

(b)

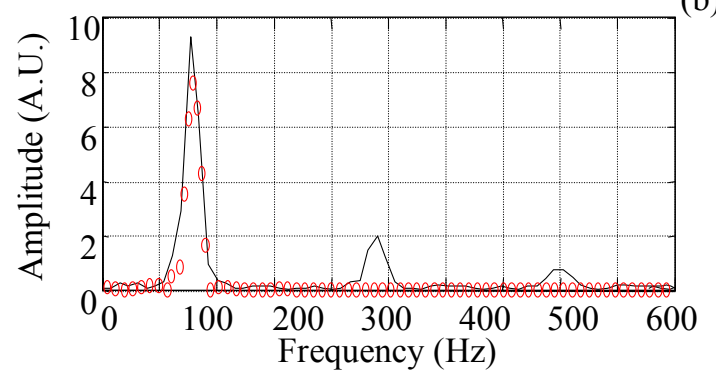

Figure 3: Experimental particle velocities as function of time measured at a point located at $15 \mathrm{~mm}$ away from the source (a) and its normalized spectrum (b). The central frequency of the emitted signal is $100 \mathrm{~Hz}$. Experimental spectrum of the acceleration signal measured on the source (circles).

\section{NONLINEAR INTERACTION BETWEEN TRANSVERSE WAVES}

As in the case of shock transverse wave, nonlinear interaction between transverse waves is an effect one order smaller than between longitudinal waves. In the latter case, the nonlinear interaction between two primary waves $\omega_{1}$ and $\omega_{2}$ (respectively at 100 and 140 $\mathrm{Hz}$ ) give birth to waves at frequencies $2 \omega_{1}, 2 \omega_{2}$, $\omega_{1}+\omega_{2}, \omega_{1}-\omega_{2}$. For transverse waves, from the nonlinear wave equation (6), 


$$
\begin{array}{r}
\frac{\partial^{2} v}{\partial x^{2}}-\frac{\rho_{o}}{E} \frac{\partial^{2} v}{\partial t^{2}}=-\frac{3 \gamma}{c_{o}^{2} E} \\
\frac{\partial}{\partial x}\left(v^{2} \frac{\partial v}{\partial x}\right) \\
+\frac{\chi}{E} \frac{\partial}{\partial t}\left(\frac{\partial^{2} v}{\partial x^{2}}\right)
\end{array}
$$

and using some perturbation method, one show that two primary waves $\left(\omega_{1}\right.$ and $\left.\omega_{2}\right)$ create in first approximation harmonics at the frequencies $3 \omega_{1}, 3 \omega_{2}, \omega_{1}+2 \omega_{2}, \omega_{1}-2 \omega_{2}, \omega_{2}+2 \omega_{1}, \omega_{2}-2 \omega_{1}$. In both mode (longitudinal or transverse) waves vector have to be collinear in order to give rise to a cumulative effect.
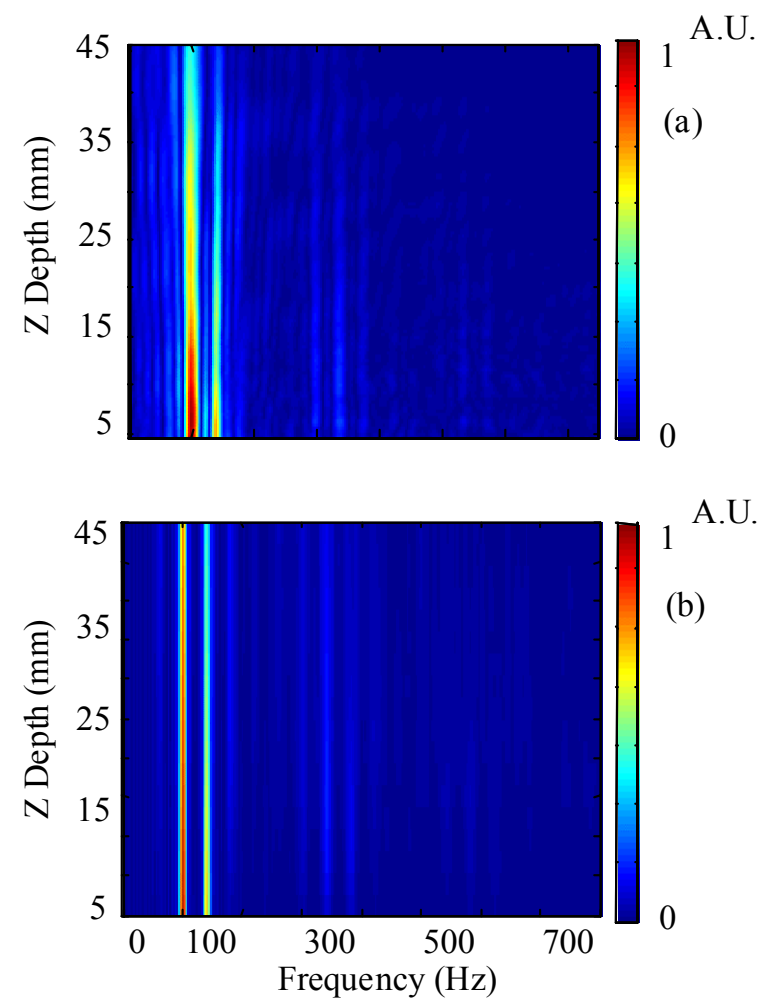

Figure 4: Experimental (a) and simulated (b) spectrum of the wave profile at each depth when two transverse waves at $\omega_{1}$ and $\omega_{2}$ are sent in an Agargelatin based phantom.

This theoretical result is well retrieved in the numerical simulation of the modified Burgers equation as well as in the experiment, Fig.4.

\section{CONCLUSION}

Although gelatin based phantoms are known to be very linear from an elastic point of view, quantitative measurements of their nonlinear behavior is possible with elastographic methods.
The experiments presented in this paper are probably still too academic to be easily applied on real soft tissues but give but give a clear illustration of the shear wave behavior in soft media. Further works are needed to investigate the non linear behavior of non plane shear waves in order to apply these techniques in vivo.

\section{REFERENCES}

[1] L. Sandrin, M. Tanter, S. Catheline and M. Fink, "Shear Modulus Imaging with 2-D Transient Elastography", IEEE trans. on UFFC 49, 426-435 (2002).

[2] J. Ophir, I. Céspedes, H. Ponnekanti, Y. Yasdi and X. Li, “Elastography: A Quantitative Method for Imaging the Elasticity of Biological Tissues ", Ultrasonic Imaging 13, 111-134 (1991).

[3] F. D. Murnaghan, "Finite Deformation of an Elastic Solid", Am. J. Math. 49, 235 (1937).

[4] D. S. Hugues, J. L. Kelly, "Second-Order Elastic Deformation of Solids", Phys. Rev. 92, 1145-1149 (1953).

[5] E. C. Everbach, R. E. Apfel, "An interferometric technique for $\mathrm{B} / \mathrm{A}$ measurement", J. Acoust. Soc. Am. 98, 34283436 (1995).

[6] S. Catheline, J.-L. Gennisson and M. Fink, "Measurement of elastic nonlinearity of soft solid with transient elastography", J. Acoust. Soc. Am. 114 (4), (2003).

[7] B.E. McDonald and J. Ambrosiano, "Highorder upwind flux correction methods for hyperbolic conservation laws", J. Comput. Phys. 56, 461 (1984).

[8] S. Catheline, J.-L. Gennisson, M. Tanter and M. Fink, " Observation of shock transverse waves in elastic media", accepted for publication in Phys. Rev. Let., (2003). 